\title{
Experimental and Theoretical Investigations of Complex Formation of Substituted Phenylazo-Derivatives of Methylphloroglucinol
}

\author{
Amangdam, A.T., Kovalchukova, O.V., Strashnova, S.B., Strashnov, P.V., \\ Romashkina, E.P., Volyansky, O.V. \\ Peoples' Friendship University of Russia, Miklukho-Maklaya street, 6, 117198 Moscow, Russia
}

e-mail okovalchukova@mail.ru

\begin{abstract}
Using spectrophotometric titration technique, the processes of complex formation of some phenylazo-derivatives of methylphloroglucinol (MPG) containing hydroxo-, nitro- and nitroso-substituents were studied. The spectral criteria of neutral and ionized forms of the organic ligands in their different tautomeric forms were determined.

It was detected that the complex formation is accompanied by formation of one or two chelate cycles which involve azo- or nitroso-fragments and neighboring $\mathrm{OH}$-groups of the organic ligands. Different types of coordination lead to different changes in the electronic absorption spectra.

The DFT-B3LYP modeling of a Ni(II) complex of $\alpha$-hydroxyphenylazo MPG established the most probable coordination mode of the organic ligand: tridentate chelating dianion, distorted square coordination of $\mathrm{Ni}$-cations including one water molecule. The theoretical results are in a good accordance with the experimental data.
\end{abstract}

\section{Indexing terms/Keywords}

Substituted phenylazo-derivatives of methylphloroglucinol; complex formation; spectrophotometric titration; quantum chemical modeling

\section{Academic Discipline And Sub-Disciplines}

Chemistry

\section{SUBJECT CLASSIFICATION}

Coordination Chemistrry

\section{TYPE (METHOD/APPROACH)}

Research paper

\section{Council for Innovative Research}

Peer Review Research Publishing System

Journal: Journal of Advances in Chemistry

\author{
Vol. 4, No. 1 \\ editor@cirworld.com \\ www.cirworld.com, member.cirworld.com
}




\section{INTRODUCTION}

2,4,6-Trihydroxytoluene (methylphloroglucinol, MPG) possesses strong and attractive synthetic potential because of its specific structure. However, till recent years when the economically efficient method of synthesis of MPG on base of 2,4,6trinitrotoluene [1,2] was developed, it practically has not been realized. It is well known that hydroxyazo compounds possess properties of dyes and pigments which colorizing characteristics strongly depend on ability of their complexation with metals [3]. The introduction of other electron donating fragments (keto-, hydroxy-, nbitroso-, hydroxylamino-, etc.) leads to the multiplicity of the ionic ant tautomeric equilibria as well as coordination modes.

This paper is aimed at explanation of new results obtained when experimental and theoretical studying the processes of complex formation of some polyfunctional phenylazo-derivatives of methylphloroglucinol (MPG).

\section{EXPERIMENTAL PART}

\section{Reagents and solutions}

The polyfunctional phenylazo-derivatives of methylphloroglucinol (Figure 1) were prepared according to the procedures described previously $[4,5]$. The other chemicals were used as received.

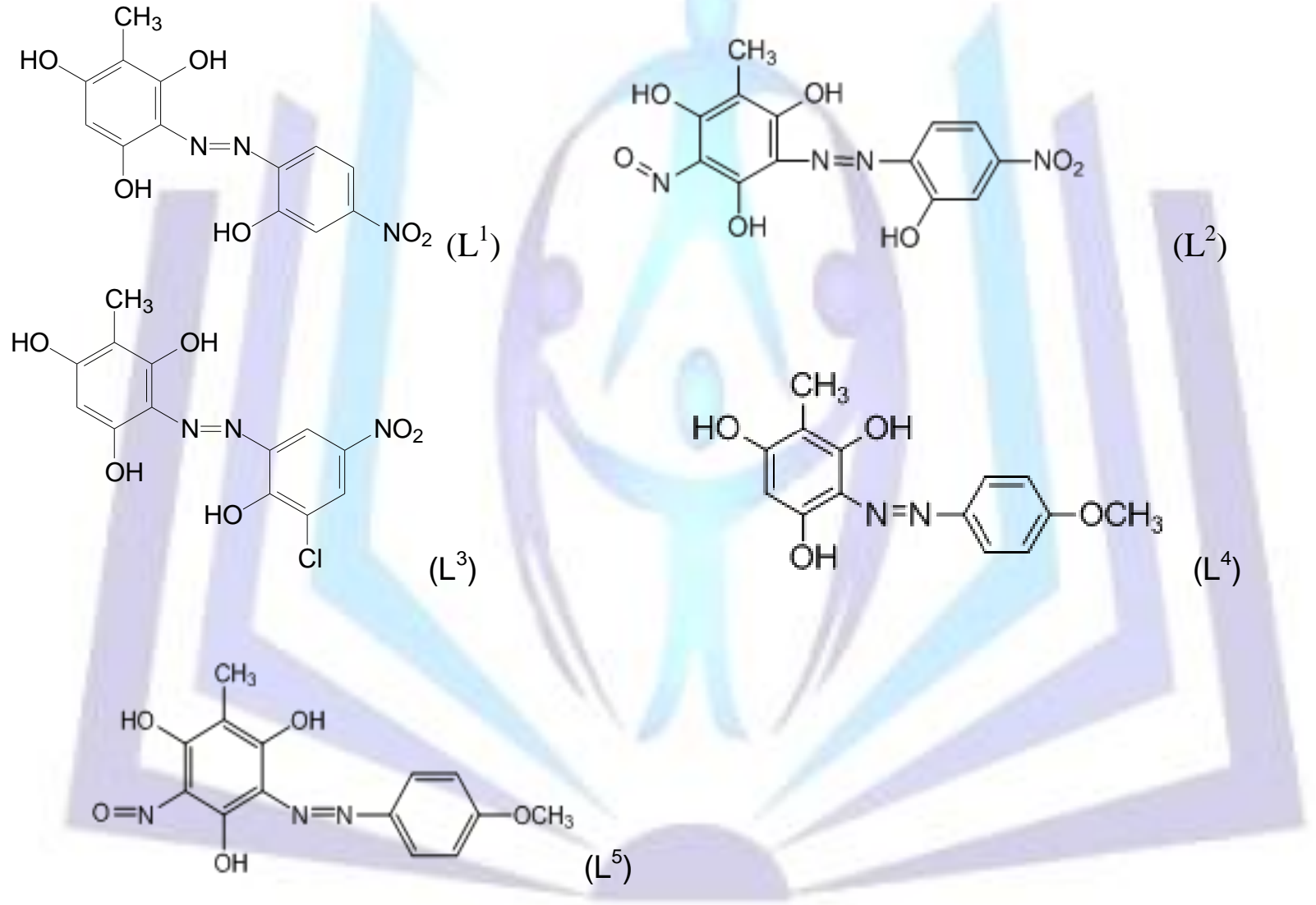

Fig. 1: The MPG phenylazo-derivatives used in the present work.

\section{Apparatus and equipment}

UV-VIS spectra were recorded in the range of $200 \mathrm{~nm}$ to $800 \mathrm{~nm}$ using a Varian Cary 50 Scan spectrophotometer. Calculations of ionization constants were performed according to the procedure described in [6].

The geometry optimization of tautomers was performed by means of DFT-B3LYP/aug-cc-pVDZ approach. Electronic absorption spectra were predicted using TDDFT approach at the same theory level as geometry optimization. In TDDFT calculations, the bulk solvent effects were taken into account by means of polarizable continuum model (PCM). The LANL2DZ pseudo-potential was used for Ni-atoms [7]. All the calculations were performed with FireFly package [8]. 


\section{RESULTS AND DISCUSSION}

As it is evident from the structures of $\mathrm{L}^{1}-\mathrm{L}^{5}$, nitroso-hydroxyimino (II, III) and azo-hydrazo (IV - VI) tautomeric forms can exist in solutions (Figure 2).<smiles>C#CC#CON=C1C(=O)C(C)=C(O)C(=NNc2ccc([N+](=O)[O-])cc2O)C1Oc1ccc(N=Nc2c(O)c(C)c(O)c(N=O)c2N=O)c(O)c1N=Nc1ccc([N+](=O)[O-])cc1O</smiles>

2:. Some possible tautomeric forms of $\mathrm{L}^{2}$

Fig.

As it was previously reported [4], the dinitroso-substituted MPG exists in the form of a dihydroxyimino-tautomer, the ionization of which provokes the hypsochromic shift of the long-wave absorption band in the UV-VIS spectra. From the other side, the most stable tautomers of monoazo-substituted MPG are the azo-ones [9]. The titration by alkalis leads to the batochromic shift of the long-wave band in the spectra of these compounds (Figure 3).

In the case of $L^{2}$ and $L^{5}$ azo-nitroso compounds, the change in the long-wave absorption band at the addition of $\mathrm{NaOH}$ is similar to that of the donitroso-derivative of MPG (Figure 4).

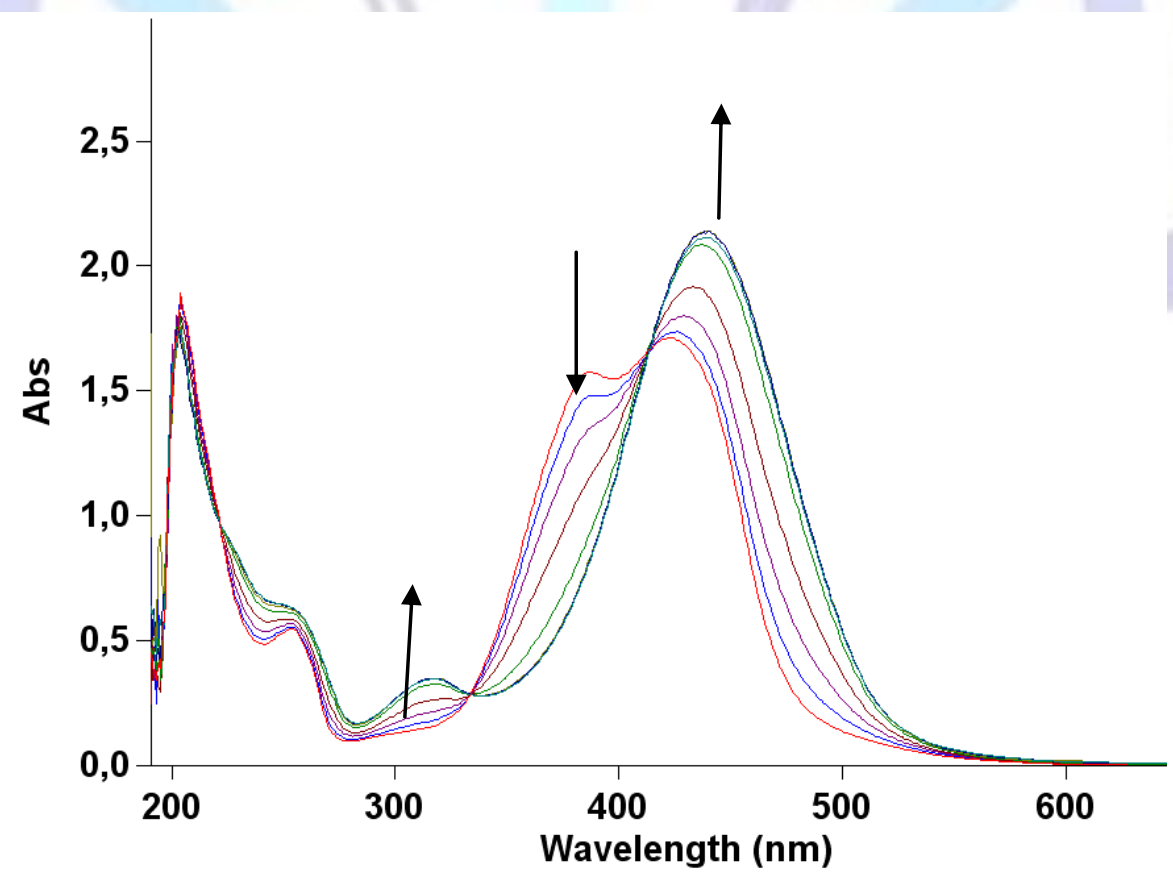

Fig. 3: Changes in the UV-VIS spectra of ethanol solutions of $\mathrm{L}^{4}$ in the $\mathrm{pH}$ interval 5.5 - 11.0. 


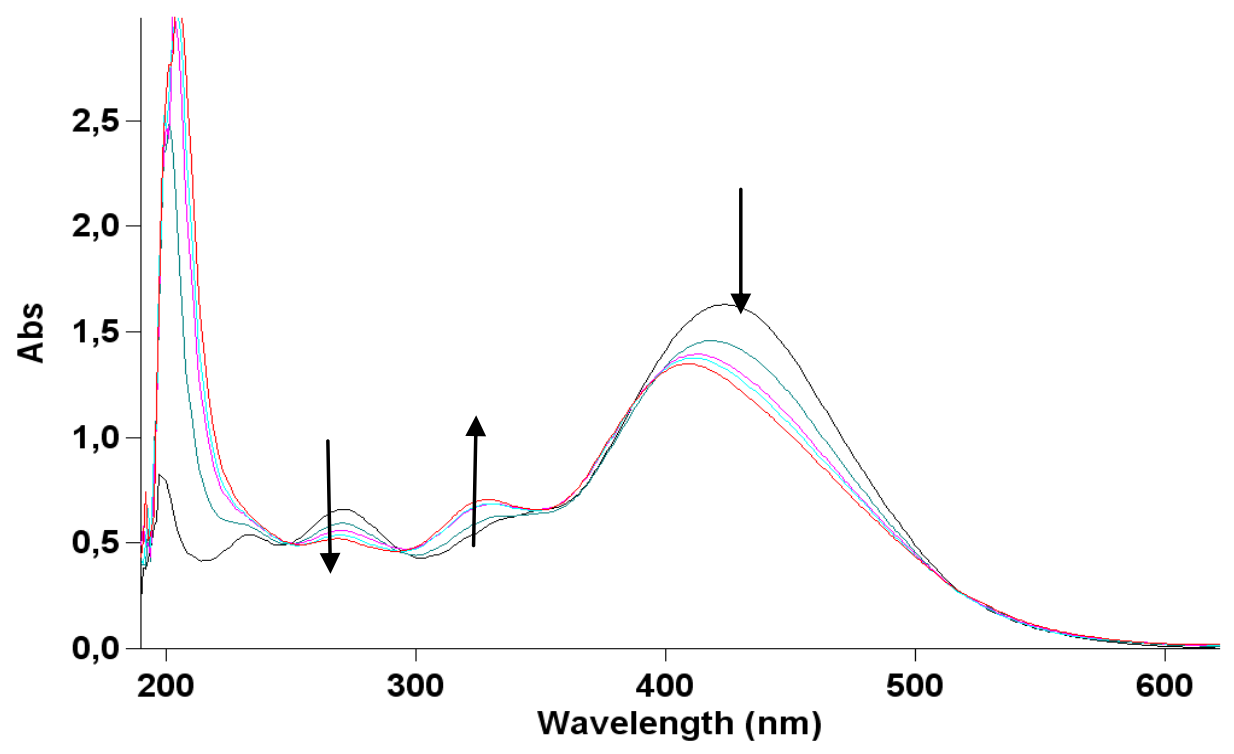

Fig. 4: Changes in the UV-VIS spectra of ethanol solutions of $\mathrm{L}^{5}$ in the $\mathrm{pH}$ interval 4.7 - 10.7.

These facts may indicate that $L^{2}$ and $L^{5}$ exist in the solutions in the forms of azo-hydroxyimino tautomers II and III. The ability of the tautomer III to be stabilized by an intramolecular $\mathrm{H}$-bond between the neighboring $=\mathrm{NOH}$ and $\mathrm{C}=\mathrm{O}$ groups makes it more preferable. The ionization process involves nitroso-group better than hydroxyl-groups.

The addition of ethanol solutions of transition metals salts to the ethanol solutions of the organic species until one-to-one $\mathrm{M}: \mathrm{L}$ molar ratio provokes the same type of the change in the UV-VIS absorption spectra as at ionization of the ligands (Figures 5,6 ). This can be explain by the following. The complexation of $\mathrm{L}^{1}, \mathrm{~L}^{3}$, and $\mathrm{L}^{4}$ passes through the formation of a metal chelate ring involving one of the $\mathrm{N}$-atom of the azo-group and a neighboring $\mathrm{O}$-atom of a deprotonated $\mathrm{OH}$ group. In the case of $L^{2}$ and $L^{4}$, the chelating occurs through the ionized hydroxyimino-group and a neighboring carbonyl-group.

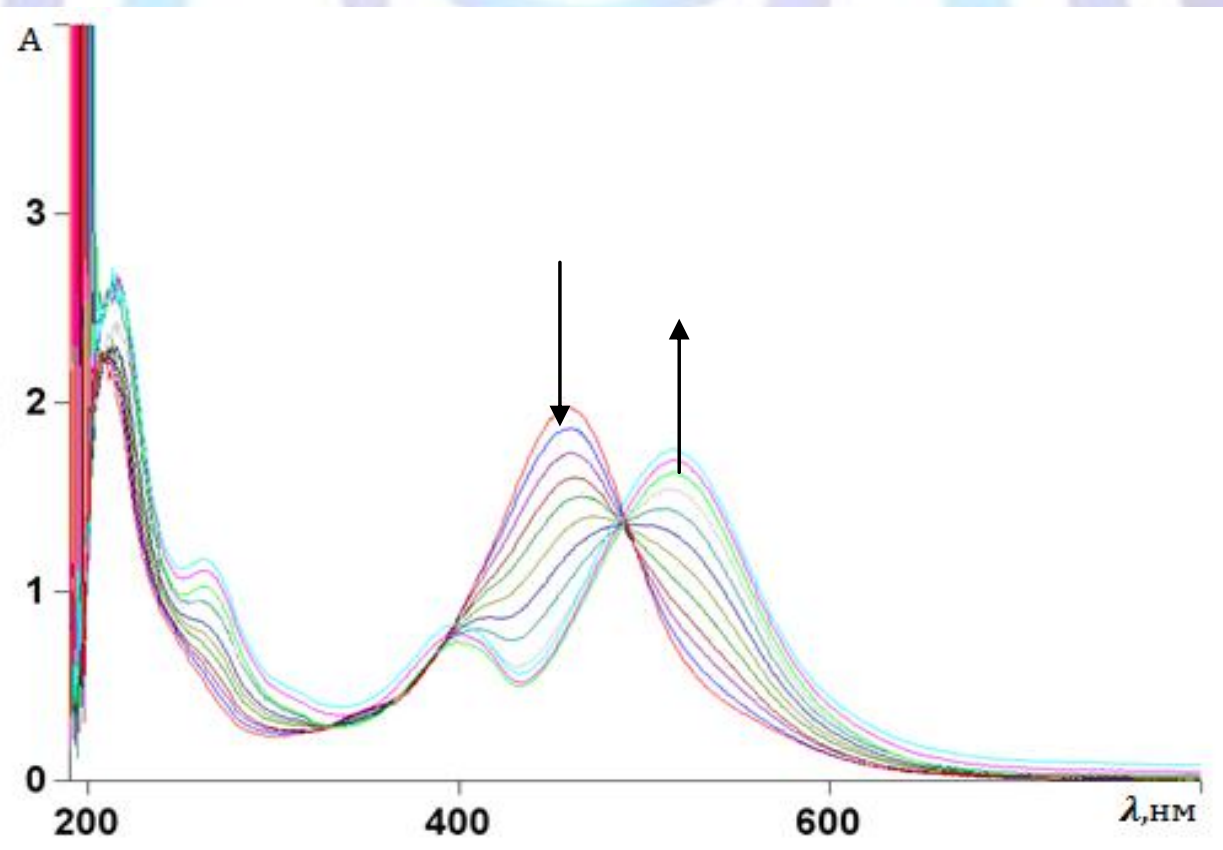

Fig. 5: Changes in the UV-VIS spectra of ethanol solutions of $L^{1}$ after stepwise addition of the ethanol solution of $\mathrm{CuCl}_{2}$. 


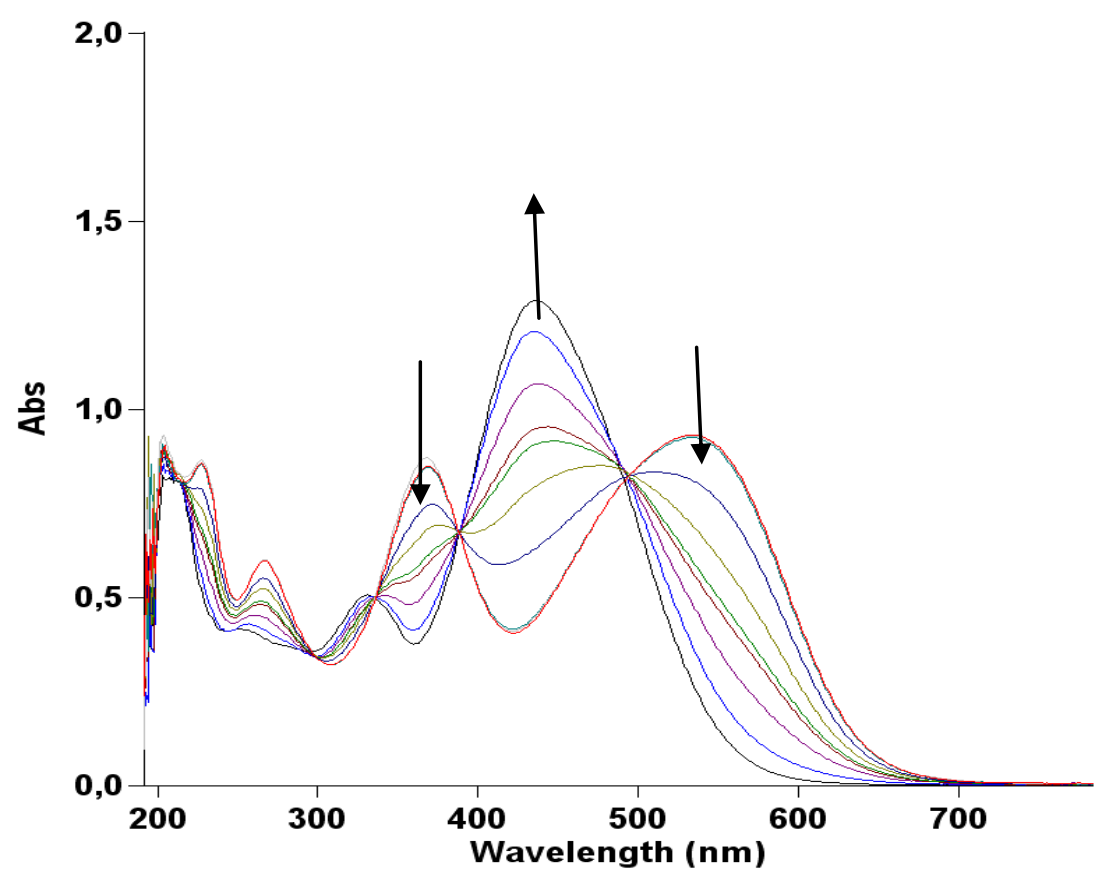

Fig. 6: Changes in the UV-VIS spectra of ethanol solutions of $\mathrm{L}^{2}$ after stepwise addition of the ethanol solution of $\mathrm{CuCl}_{2}$.

In order to prove our proposals, the modeling of the structure of the Ni-complex with the ligand $L^{1}$ was performed using DFT-B3LYP procedure. As it was shown, the optimized geometric structure contains slightly disturbed square coordinated $\mathrm{Ni}^{2+}$ cation which is coordinated to an $\mathrm{L}^{1}$ dianion through two ionized $\mathrm{OH}$ groups of the MPG and benzene rings correspondently and one of the $\mathrm{N}$-atoms of the azo-group. Thus a 5- and a 6-membered chelate rings are formed in one time. One water molecule is also involved in coordination (Figure. 7).

The position of the long-wave absorption band in the calculated UV-VIS spectrum of the above complex (452 $\mathrm{nm})$ and the character of its splitting is in a good agreement with the position and the shape of the experimental data $\left(\lambda_{\max } 469 \mathrm{~nm}\right)$.

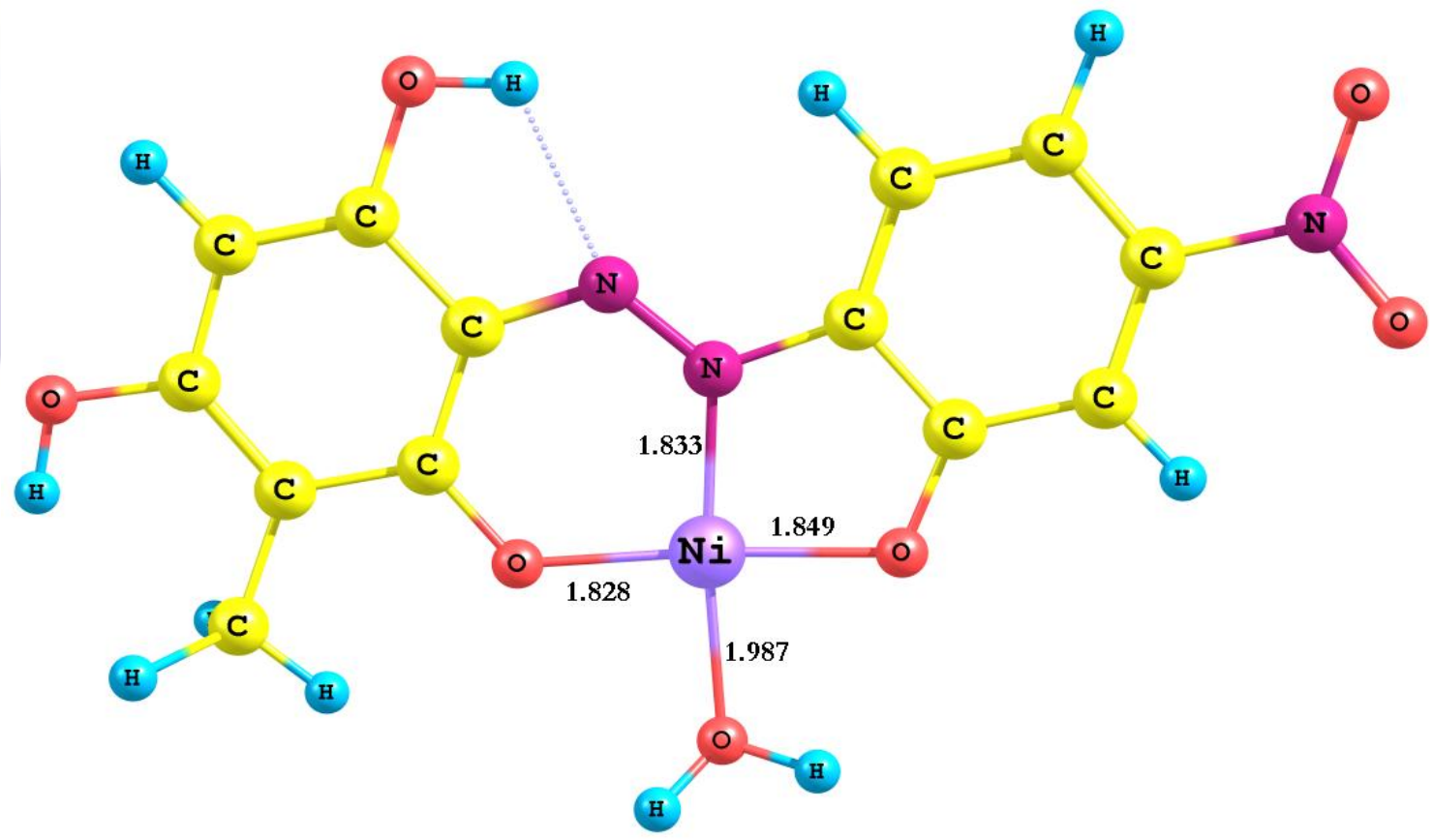

Fig. 7: The optimized structure of the $\mathrm{Ni}-\mathrm{L}^{1}$ complex and some bond lengths (in $\AA$ ) 


\section{ACKNOWLEDGMENTS}

The researches were supported by the Russian Foundation for Basic Research, project no. 13-03-00079-a. All the calculations have been executed using the "SKIF-Chebyshev" supercomputer of the Moscow State University.

\section{REFERENCES}

[1] Atkins, W. S., and Wilson, J. 1986. Synthesis of polynitrodiazophenols. J. Org. Chem., 51 (June 1986), $2572-2578$.

[2] Shevelev, S. A., Shakhnes, A. Kh., Ugrak, B. J., and Vorob'ev, S. S. 2001. Highly selective one-step synthesis of 2 amino-4,6-dinitrotoluene and 2,6-diamino-4-nitrotoluene from 2,4,6-trinitrotoluene. Synth. Commun., 37 (September 2001), 2557-2561.

[3] Venkatarman, K. 1971. The Chemistry of Synthetic Dyes.

[4] Kovalchukova, O., Dinh Do, N., Stash, A., Bel'sky, V., Strashnov, P., Alafinov, A., Volyansky, O., Strashnova, S., and Kobrakov, K. 2012. Crystal and Molecular Structure, and Spectral Characteristics of Sodium 3,5-Bis(Hydroxyimino)-1Methyl-2,4,6- Trioxocyclohexanide. Crystal Structure Theory and Applications, 1 (January 2012), 46-51.

[5] Stankevich, G. S., Kobrakov, K. I., Volyansky, O. V., Kovalchukova, O. V., Ushkarev, V. I., Alafinov, A. I., Shakhness, A. Kh., Dutov, M. D., Shevelev, S. A., Strashnov, P. V., and Romashkina, E. P. 2010. Trinitrotoluene as a precursor in synthesis of effective azodyes and azopygments. In Proceedings of the 13th Seminar on New Trends in Research of Energetic Materials. Proceedings of the 13th Seminar on New Trends in Research of Energetic Materials.

[6] Nagypal, J., and Beck, M. T. 1980. Rules governing concentration distribution in complex equilibrium systems. J. Phys. Chem., 84 (April 1980), 722-726.

[7] Hay, P. J., and Wadt, W. R. 1985. Ab initio effective core potentials for molecular calculations. Potentials for the transition metal atoms Sc to Hg. J. Chem. Phys., 82 (January 1985), 270-284.

[8] Granovsky A.A. Firefly version 7.1.G, www http://classic.chem.msu.su/gran/firefly/index.htm

[9] Kovalchukova, O. V., Strashnova, S. B., Strashnov, P. V.,Romashkina, E. P., Volyansky, O. V., and Kobrakov, K. I. 2011. Spectral and quantum chemical studies of tautomeric and ionic transformations of azo-dyes based on methylfloroglucinol (in Russian). Butlerov communications, 24 (May 2011), 90-94. 